\title{
BMJ Open Quality Improving medication reconciliation at hospital admission, discharge and ambulatory care through a transition of care team
}

\author{
John Kreckman, ${ }^{1}$ Waiz Wasey, ${ }^{1}$ Sharron Wise, ${ }^{1}$ Tammy Stevens, ${ }^{1}$ Lance Millburg, ${ }^{2}$ \\ Cassie Jaeger ${ }^{2}$
}

To cite: Kreckman J, Wasey W, Wise S, et al. Improving medication reconciliation at hospital admission, discharge and ambulatory care through a transition of care team.BMJ Open Quality 2018;7:e000281. doi:10.1136/ bmjoq-2017-000281

Received 6 December 2017 Revised 5 February 2018 Accepted 7 April 2018
Check for updates

${ }^{1}$ Department of Family and Community Medicine, Southern Illinois University School of Medicine, Springfield, Illinois, USA

${ }^{2}$ Memorial Health System, Springfield, Illinois, USA

Correspondence to Dr John Kreckman; jkreckman52@siumed.edu

\section{ABSTRACT}

Medication reconciliation is an important component to the care of hospitalised patients and their safe transition to the ambulatory setting. In our Family Medicine Hospitalist Service, patient care is frequently transferred between the various physicians, residents, nurses and eventually to a separate group of providers who provide ambulatory management. Due to frequent transitions of care, there was no clear ownership of the medication reconciliation process. To improve the medication reconciliation process, a Transition of Care Team composed of registered nurses was created to oversee the entire reconciliation process. The team engaged the patient and their family, when needed, contacted patients' pharmacies and their providers, reconciled the patients' hospital medication list with the ambulatory list at hospital admission and within 24 hours of discharge, and attended the hospital followup visit to verify medications and provide continuity of care. Implementation of the team allowed for additional investigative resources, redundancy in preventing errors and early recovery should an error occur. The percent of medications with error after implementation of the Transition of Care Team was reduced from 131/386 (33.9\%) to $147 / 787(18.7 \%)$ at hospital admission, $81 / 354(22.9 \%)$ to $42 / 834(5.0 \%)$ at discharge and $43 / 337(12.8 \%)$ to $6 / 809(0.7 \%)$ at follow-up visit (two proportion tests, $\mathrm{p}<0.001)$. In addition, the percent of charts without any errors improved at hospital discharge from $8 / 31(25.8 \%)$ to $46 / 70(65.7 \%)$ and at hospital follow-up visit from 16/31 (51.6\%) to 64/70 (91.4\%) (two-proportion test, $p<0.001)$. Previously viewed as three separate reconciliations occurring at admission, discharge and hospital follow-up, the approach to medication reconciliation was reframed as a continuous process occurring throughout the hospitalisation and hospital follow-up resulting in improved reconciliation accuracy and safer transitions to the ambulatory setting.

\section{PROBLEM}

The Family Medicine Hospitalist Service (FMHS) at our 500-bed tertiary-care facility in Illinois, USA, provides a broad range of inpatient services. Based on case mix index and average severity level, the FMHS patient population is representative of the institutional patient population. The hospital service is composed of one attending physician and five residents who divide the day, night and weekend responsibilities on a rotational basis. Patient care is frequently transferred between the various team members and eventually to a separate group of providers who provide ambulatory management. The hospital electronic medical record does not interface with the ambulatory record of the residency programme. Information between the two records is transmitted in portable document format. Consequently, manually updating medication records at the end of the hospital stay is a time-consuming process and is subject to human error. An initial audit of 30 ambulatory records of recently hospitalised patients in May 2016 revealed that 20/30 $(66.0 \%)$ records had medication errors at the hospital follow-up visit.

\section{BACKGROUND}

In 2016, medical errors were estimated to result in 250000 deaths annually, making medical errors the third leading cause of death in the USA. ${ }^{1}$ Drug-related errors are the most common type of medical error and can result from discrepancies in patient medications during periods of transition of care. $^{23}$ Around $60 \%$ of medication errors occur during patient admission, discharge or transfer of care. ${ }^{4}$ It is estimated that at least one medication error occurs each day for an average hospitalised patient. ${ }^{5}$ Belda-Rustarazo et al reported that $64.5 \%$ of patients had at least one medication reconciliation error at hospital admission. ${ }^{6}$ The percent of patients with one or more medication discrepancy at hospital discharge has been reported at $14.1 \%$ and $32.4 \% .^{67}$ Of the errors discovered at hospital discharge in a prospective observational study, $51 \%$ had the potential to result in moderate to severe harm. ${ }^{6}$ 
In a prospective study of 400 discharged patients, $66 \%$ of adverse events that occurred were adverse drug events and one-third of all adverse events were considered preventable. ${ }^{8}$ Medication reconciliation, a comparison of a patient's medication list with the physician's for accuracy of drug type, dose, frequency and route of medication at hospital admission, transfer and discharge, can reduce medication errors. ${ }^{9}$ However, a challenge often faced by institutions is that there is no clear owner of the medication reconciliation process. ${ }^{9}$ In 2011, The Joint Commission incorporated medication reconciliation into a National Patient Safety goal and required organisations to 'maintain and communicate accurate medication information' and 'compare the medication information the patient brought into the hospital with the medications ordered for the patient by the hospital in order to identify and resolve discrepancies' ${ }^{10}$ In a previous study, implementing medication review by a pharmacist at hospital admission and creating a discharge medication reconciliation form and report that patients can take home with them reduced medication errors from $57 \%$ to $33 \% .^{11}$

\section{BASELINE MEASUREMENT}

The accuracy of medication reconciliation was measured at admission, discharge and hospital follow-up. A medication error was defined as any incorrect labelling, inclusion or exclusion of a medication that the practitioner believed was likely to result in incorrect usage. A medication was included if it was provider rather than patient directed. For example, omeprazole or aspirin, both available over the counter, were included, but only if directed by the provider. Each medication error was counted once even if it had more than one error. If omeprazole was written as $20 \mathrm{mg}$ daily but should have been written as $40 \mathrm{mg}$ twice daily, it would only be counted as one error even though both the dose and the frequency were incorrect. Percentages were calculated using the number of discrete errors in the numerator and the total number of discrete medications in the final reconciled list as the denominator with an error rate limited to $100 \%$. The same definition of a medication error was used for the initial audit, preintervention chart review and postintervention chart review.

Before initiation of the project, the admission reconciliation consisted of a two-step verification process performed by hospital nursing staff trained to perform the task. Following medication verification from at least two sources, typically with the patient's primary care office, preferred pharmacy and/or previous discharge summary or history from the physician, the nursing staff populated the medication list into the hospital electronic record and forwarded it to the FMHS resident for verification and signature. Due to the time required for completion of the two-step verification, frequently the verifying resident was not the same resident who actually admitted the patient.
During the hospital course, medications are added, removed and adjusted by various FMHS team members as well as other services involved in the patient's care. At the time of discharge, the final medication lists are reconciled back into the ambulatory record by the discharging resident and then forwarded to the patient's primary care provider for verification.

At the hospital follow-up visit, the previously reconciled ambulatory record is reviewed by nursing staff and verified by the treating resident. In almost all cases, the admitting, verifying, discharging and hospital follow-up visit residents are different individuals each having varying levels of involvement in the patient's care (figure 1). Staff spend approximately $30 \mathrm{~min}$ at hospital admission and $10 \mathrm{~min}$ at hospital discharge and follow-up completing the medication reconciliation process.

A second chart review of 31 records of recently hospitalised patients completed 2 months prior to the intervention, defined as preintervention, revealed that 131/386 $(33.9 \%)$ of medications contained errors at hospital admission, 81/354 (22.9\%) of medications contained errors at discharge and 43/337 (12.8\%) of medications contained errors at the hospital follow-up visit. Only $7 / 31(22.6 \%)$ charts at admission, 8/31 (25.8\%) charts at discharge and $16 / 31(51.6 \%)$ charts at the hospital follow-up visit did not contain any errors.

\section{DESIGN}

In June 2016, FMHS staff were educated on medication reconciliation, FMHS's current medication error rate, and began participating in chart reviews for preintervention data collection. Using the Lean Six Sigma model of Define, Measure, Analyse, Improve and Control, the medication reconciliation inaccuracy was evaluated. Process mapping and a failure modes effect analysis was used to analyse the FMHS medication reconciliation process. Lean Six Sigma methodology determined that the primary cause of inaccurate medication reconciliation was its silo structure. Admission, discharge and hospital follow-up, along with their coinciding medication reconciliations, were treated as separate processes. As three separate processes performed by different individuals, medication reconciliation lacked ownership making feedback and accountability difficult. To remove the silo structure, a Transition of Care Team, with ownership of the entire reconciliation process, was created. The Transition of Care Team was implemented in November 2016. A preinterventionpostintervention design was chosen in order to include all patients in the intervention, meet Joint Commission's National Patient Safety goal for medication reconciliation and to help reduce medication error risk.

The percent of charts and medications with errors was measured by a convenience sample in June, July and August 2016 preintervention and November 2016, December 2016 and January, March, June and September 2017 after the intervention. Patient age, gender, severity of illness, length of stay, complications of care, 30-day 


\begin{tabular}{|c|c|c|}
\hline Admission & Hospitalization and Discharge & $\begin{array}{l}\text { Hospital } \\
\text { Follow Up }\end{array}$ \\
\hline $\begin{array}{l}\text {-Nursing staff verifies } \\
\text { medications from } 2 \\
\text { sources } \\
\text {-Nursing staff updates the } \\
\text { hospital electronic record } \\
\text { and notifies resident } \\
\text {-Resident verifies list and } \\
\text { signs off on }\end{array}$ & $\begin{array}{l}\text {-Medications added/removed/changed } \\
\text { during hospitalization } \\
\text {-Discharge reconciliation in the hospital electronic } \\
\text { record and the ambulatory record } \\
\text {-Discharge is completed and discharge summary flows } \\
\text { to the ambulatory record } \\
\text {-Primary Care Physician tasked to review reconciled } \\
\text { ambulatory list } \\
\text {-Verbal sign out to follow up provider }\end{array}$ & $\begin{array}{l}\text {-Transition of Care Team } \\
\text { verifies medications with } \\
\text { patient and reconciles the } \\
\text { ambulatory list } \\
\text {-Resident verifies list with } \\
\text { patient and reconciles } \\
\text { ambulatory list } \\
\text {-Ambulatory reconciliation } \\
\text { complete }\end{array}$ \\
\hline \multicolumn{3}{|c|}{ Transition of Care Team } \\
\hline $\begin{array}{l}\text { Reconciles medications with } \\
\text { the ambulatory record and } \\
\text { provides corrected list to } \\
\text { hospital and FMHS }\end{array}$ & $\begin{array}{l}\text { Reviews the reconciled ambulatory record against the } \\
\text { patient's discharge summary within } 24 \text { hours of discharge } \\
\text { and provides feedback to FMHS }\end{array}$ & $\begin{array}{l}\text { Participates in follow up visit } \\
\text { list reconciliation and } \\
\text { discharge management plan }\end{array}$ \\
\hline
\end{tabular}

Figure 1 Medication reconciliation process at hospital admission, discharge and follow-up visit. At hospital admission, nursing staff complete a two-step verification of medications, update the electronic record and notify the resident to sign off on the list. At discharge, medications are reconciled in the hospital and ambulatory records are forwarded to the patient's provider. At hospital follow-up visit, both nursing staff and residents verify the medication list. Frequently, the admitting, verifying, discharging and hospital follow-up residents are different individuals. The Transition of Care Team begins ambulatory medication reconciliation at admission, reviews the list again within 24 hours of discharge and attends the follow-up visit to provide continuity of care. Use of the Transition of Care Team removed the silo structure of the initial medication reconciliation process. FMHS, Family Medicine Hospitalist Service.

readmission and mortality rate were measured for the Family Medicine Hospitalist service from the Crimson database 12 months before and after the initial educational intervention in June 2016. Complications of care are based on International Classification of Diseases codes for complications of a device, implant or graft, surgical procedure or from medical care that occurred during the hospital stay. Two-proportion tests were used to determine differences in the percent of medications with errors, the percent of charts without errors, gender, severity of illness, complications of care, 30-day readmission and mortality rate before and after the intervention. Chi-square analysis was used to determine differences in severity of illness, determined by All Patient Refined Diagnosis Related Groups. Mann-Whitney U tests were performed to determine differences in patient age and length of stay. A $\mathrm{P}$ value of $<0.05$ was considered significant.

\section{STRATEGY}

\section{Plan-Do-Study-Act 1-education-June 2016}

FMHS staff were educated on the patient benefits of accurate medication reconciliation. The current FMHS medication reconciliation performance was shared, including the percentage of charts in the initial audit in May 2016 that contained medication errors. Staff were encouraged to maintain accurate medication reconciliation and participate in the Lean Six Sigma project.

\section{Plan-Do-Study-Act 2-Transition of Care Team implemented-November 2016}

Faced with an at-risk population with low health literacy and a hospital team composed of frequently rotating residents, a transitional support structure of registered nurses was created called the Transition of Care Team. Depending on multiple factors including the complexity of the medical history, the accuracy of their personal records, the extent of family support, the number of prescribers and pharmacies, as well as the number of recent medication changes, reconciliation can be a very time-consuming process. Unencumbered by the silo structure of the hospital management, the Transition of Care Team was free to move the ambulatory record medication reconciliation from the time of discharge to the time of admission. This provided the team ample time to investigate the patient's medications.

Beginning with the patient's ambulatory medication list and comparing this with the list comprised by the hospital team, the patient and their family were then engaged, by the Transition of Care Team, to address any discrepancies. The majority of the medications are reconciled at this point. However, further investigation is occasionally needed to clarify persisting discrepancies. This deeper investigation requires a significant amount of time and includes the review of the patient's medical record, contacting the patients' pharmacies and their providers, bringing medications from home and in some cases home visits. The investigative process continues, 
gathering additional information and gradually refining the medication list until the professional satisfaction of the Transition of Care Team and the providers is met. When the Transition of Care Team determined that no further medication changes were implemented after reviewing the various prescribing sources, the reconciliation was determined complete. The reconciled ambulatory medication list is generally completed within a few days of hospital admission and is then used to provide feedback to the hospital and the FMHS teams. Medications are reviewed weekly by a Doctor of Pharmacy on the FMHS team.

Having established a reliable ambulatory medication record at the time of discharge, the discharging resident only needs to update the ambulatory list with the changes made during the inpatient stay. Within 24 hours of discharge, the Transition of Care Team reviews the reconciled ambulatory record against the patient's discharge record, providing a second opportunity for feedback and correction to the FMHS team.

At the hospital follow-up visit within 30 days after discharge, the resident reconciles the ambulatory record again updating any changes that occurred since discharge. Present at the hospital follow-up visit, the Transition of Care Team reviews the reconciled record for accuracy providing a third opportunity for feedback and correction. Having established a relationship with the patient at the time of admission, and participating in the management decisions during the patient's hospitalisation, the Transition of Care Team's presence at the hospital follow-up visit provides insight into the discharge management plan and continuity for both the resident and patient who may be meeting for the first time (figure 1).

We hypothesised that reframing reconciliation as a single continuous process beginning at hospital admission and continuing through discharge and hospital follow-up would improve the admission medication reconciliation, which would improve the discharge reconciliation, impacting the initial goal of improved medication reconciliation at hospital follow-up.

\section{RESULTS}

Following addition of the Transition of Care Team and redesign of the medication reconciliation process, the accuracy of reconciliation at admission, discharge and hospital follow-up was measured for 70 patients postintervention.

The percent medications with errors was reduced at all three junctures of reconciliation. At admission, the percent of medications with errors was reduced from $131 / 386(33.9 \%)$ to $147 / 787(18.7 \%)$ (two-proportion test, $\mathrm{p}<0.001)$. At hospital discharge, the percent of medications with errors was reduced from $81 / 354(22.9 \%)$ to 42/834 (5.0\%) (two-proportion test, $\mathrm{p}<0.001$ ). Percent medications with errors at hospital follow-up visit was reduced from $43 / 337(12.8 \%)$ to $6 / 809$ (0.7\%) (two-proportion test, $\mathrm{p}<0.001$ ) (figure 2 ). The percent of charts
Percent Medications with Errors

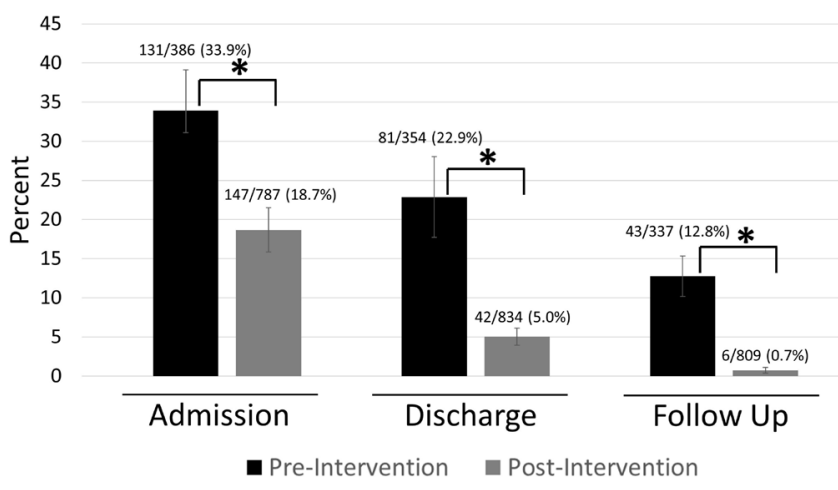

Figure 2 Percentage of medications with errors was reduced at hospital admission, discharge and follow-up visit after implementation of the Transition of Care Team. Percent medications with errors was measured by a convenience sample of 31 patients before the intervention and 70 patients after the intervention. Medication errors were counted only once even if the medication had more than one type of error. Two-proportion test, ${ }^{*} \mathrm{P}<0.001$.

without any errors improved at hospital discharge from $8 / 31(25.8 \%)$ to $46 / 70(65.7 \%)$ (two-proportion test, $\mathrm{p}<0.001)$ and at hospital follow-up visit from 16/31 $(51.6 \%)$ to $64 / 70(91.4 \%)$ (two-proportion test, $\mathrm{p}<0.001$ ) (figure 3). Severity of illness was statistically different between the pre and post groups $\left(\chi^{2}, p=0.002\right)$, with the postintervention group containing an increased percentage of patients with a severity score of 1 and a decreased percentage of patients with a severity score of 3 (two-proportion test, $\mathrm{p}<0.001, \mathrm{p}=0.037$, respectively). The percent of patients with complications of care was significantly reduced from 18/1198 (1.5\%) before the intervention to $6 / 1135(0.5 \%)$ after the intervention (two proportion test, $\mathrm{p}=0.018$ ). A decreased trend in 30-day readmissions was observed postintervention (two-proportion test, $\mathrm{p}=0.054$ ). A larger sample size may be needed to detect a statistically significant reduction in

\section{Percent of Charts without Errors}

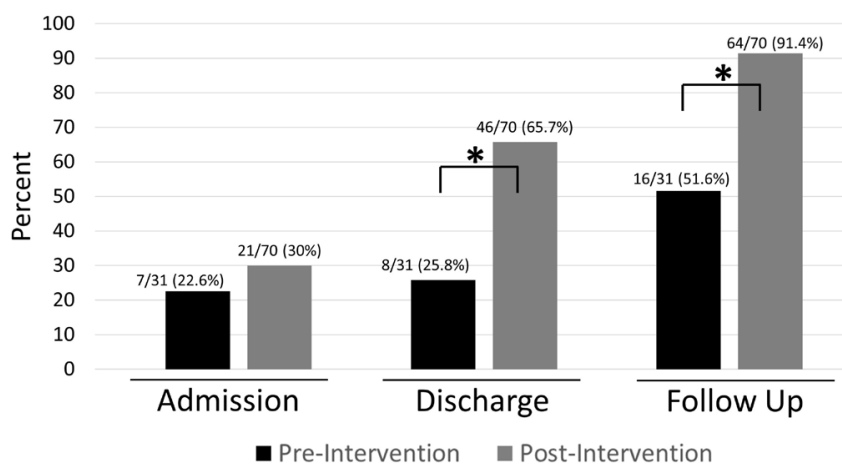

Figure 3 Percent of charts without any errors was increased at hospital discharge and follow-up visit after implementation of the Transition of Care Team. Percent charts without errors was measured by a convenience sample of 31 patients before the intervention and 70 patients after the intervention. Two-proportion test, ${ }^{*} \mathrm{P}<0.001$. 
Table 1 Complications of care were significantly reduced after implementation of the Transition of Care Team

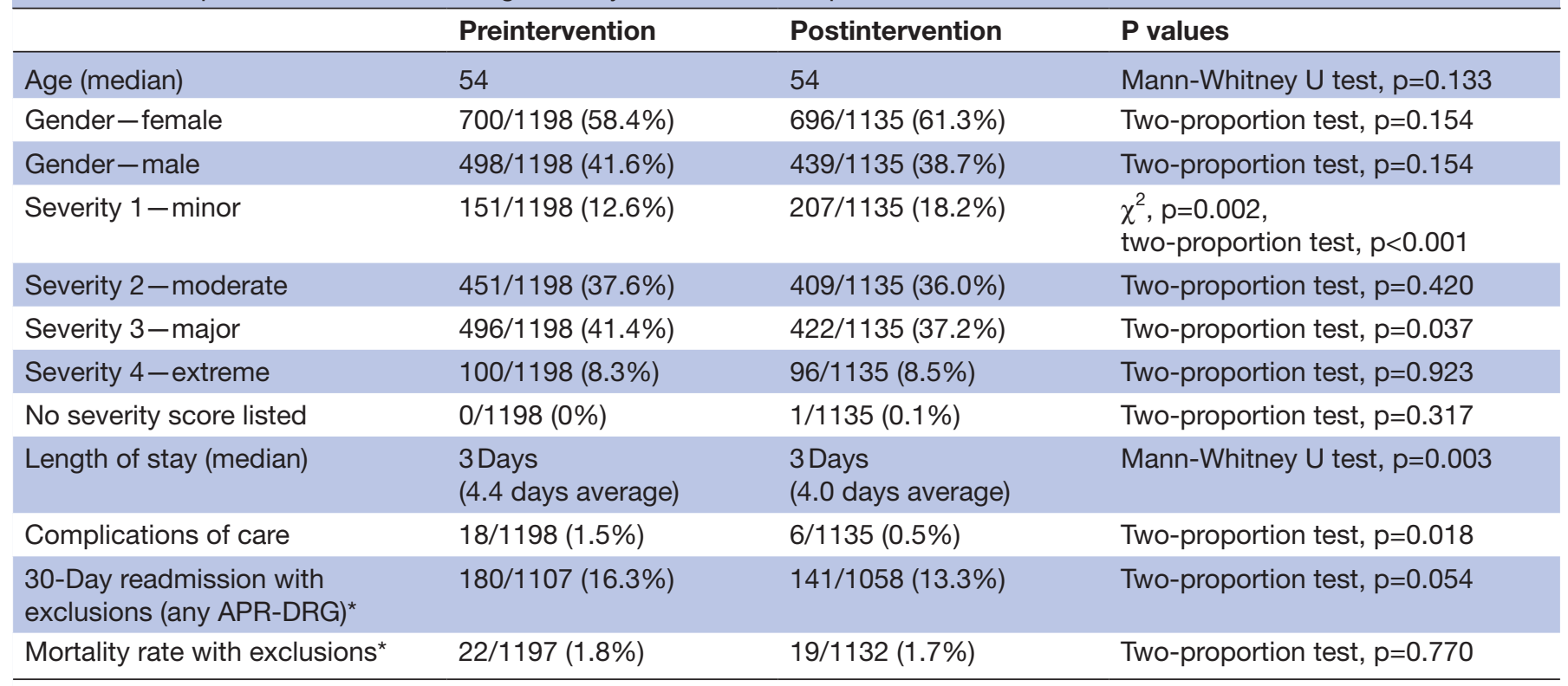

Patient characteristics were measured for the Family Medicine Hospitalist service from the Crimson database 12 months before and after the intervention.

${ }^{*}$ Crimson 30-day readmission excluded Centers for Medicare and Medicaid Services (CMS) approved readmissions including chemotherapy, radiotherapy, dialysis, rehabilitation, elective admission, patients discharged against medical advice, mortalities, length of stay greater than 1 year and transfers to other acute-care facilities. All severity adjusted All Patient Refined Diagnosis Related Groups (APR-DRGs) were included in the readmission data. Mortality rate excluded cases with uncertainty of how much influence the physician had on the case including chemotherapy and radiotherapy patients, length of stay over 1 year, inpatient transfers from other acute-care facilities and hospice patients according to Crimson guidelines.

30-day readmission rates. We continue to monitor 30-day readmission rates for FMHS. There were no significant differences in patient age, gender or mortality rate preintervention and postintervention (table 1).

To sustain the process improvements and prevent drift back to baseline, the FMHS implemented a control plan that measures medication reconciliation accuracy quarterly. Beginning with a single registered nurse, the Transition of Care Team has grown to include three fulltime employees as the team's value and responsibilities have increased to include paediatrics and newborns. Implementation of the Transition of Care Team has led to 6 months of sustained improvement in reconciliation accuracy.

\section{Lessons and limitations}

Viewed as a value chain, hospital management is the sum of each of its core processes. The admission, discharge and transition to the ambulatory care environment is a service stream composed of many nested core processes each adding either value or waste to the patient's care. A key component of process improvement that is often overlooked is the necessity of building support structures that enhance the efficiency of the core processes.

This study is unique in that the Transition of Care Team was composed of registered nurses. Most institutions rely on pharmacists to perform medication reconciliation, consuming a significant amount of their time and taking them away from other responsibilities. ${ }^{3}$ However, the success of our intervention was as effective as pharmacy-led interventions in the literature. For example, Murphy et al, implemented a team of pharmacists to complete medication reconciliation within 24 hours of admission and reduced the percent of medication errors at discharge from $57 \%$ to $33 \%$, compared with $22.9 \%$ to $5.0 \%$ in our study (figure 2). ${ }^{11}$ Scarsi et al increased the number of patients without a medication error during hospitalisation from $22.9 \%$ to $40 \%$ by including pharmacists in daily medical rounds, compared with $25.8 \%$ to $65.7 \%$ in our study (figure 3). ${ }^{12}$

According to Karnon et al, interventions that improve medication reconciliation are cost-effective for preventable adverse drug events compared with no intervention. However, their review found that nurses took a longer duration of time to complete medication reconciliation when using a standardised patient history form compared with pharmacy driven reconciliation, increasing the costs of nursing interventions. ${ }^{13}$ Although additional information is needed to make a direct comparison, the nursing-based intervention at our institution allowed pharmacists to focus on other responsibilities and was considered a cost-effective investment to provide great patient care.

The Transition of Care Team support structure provides two opportunities. First, the addition of the Transition of Care Team allowed the FMHS to reframe medication reconciliation into a single continuous process beginning at admission and continuing through the follow-up visit. In this way, each subsequent reconciliation builds on 
the accuracy of the previous one. Second, by providing additional investigative resources at admission as well as a mechanism for immediate feedback and accountability to the FMHS team, the team provides redundancy to prevent errors and a recovery mechanism to detect and correct errors before causing patient harm.

Complications of care were significantly reduced postintervention. Although encouraging, we cannot claim differences are direct outcomes of the intervention due to the complexity of patient outcomes and potential confounders including differences in severity of illness (table 1). A limitation of the study was that it was performed at a single institution and results cannot be generalised.

Finally, applying lessons learnt from the Transition of Care Team's management of medication reconciliation, the FMHS is currently looking into other opportunities to leverage the team's support to other core process including assessment for social determinants of health, scheduling ambulatory appointments, transitional phone support and implementation of the discharge plan.

\section{CONCLUSION}

Team-based care using multiple providers often results in no clear ownership of the medication reconciliation process. Creating of a Transition of Care Team of registered nurses restructured medication reconciliation as a continuous process occurring throughout patient hospitalisation, discharge and hospital follow-up and improved medication reconciliation accuracy, care of hospitalised patients, and led to safer transitions to the ambulatory setting.

Contributors JK contributed to the study concept and design, acquisition of data, analysis of data, critical review of the manuscript and study supervision. JK is responsible for the overall content as guarantor. WW contributed to the drafting and critical revision of the manuscript. LM contributed to acquisition and analysis of the data. TS and SW contributed to acquisition of the data and administrative support. CJ contributed to data analysis, drafting of the manuscript and critical revision to the manuscript. All contributors reviewed the manuscript.

Funding The transition of care team is funded by the Department of Health and Human Services Section 330: Grant \# H80CS25098.

Competing interests None declared.

Patient consent Not required.
Ethics approval This project was reviewed by the local institutional review board. It was determined that this project was not research involving human subjects.

Provenance and peer review Not commissioned; externally peer reviewed.

Open Access This is an Open Access article distributed in accordance with the Creative Commons Attribution Non Commercial (CC BY-NC 4.0) license, which permits others to distribute, remix, adapt, build upon this work non-commercially, and license their derivative works on different terms, provided the original work is properly cited and the use is non-commercial. See: http://creativecommons.org/ licenses/by-nc/4.0/

(C) Published by the BMJ Publishing Group Limited. For permission to use (where not already granted under a licence) please go to http://www.bmj.com/company/ products-services/rights-and-licensing/

\section{REFERENCES}

1. Makary MA, Daniel M. Medical error-the third leading cause of death in the US. BMJ 2016;353:i2139.

2. Roehr B. Institute of medicine report strives to reduce medication errors. BMJ 2006;333:220.

3. Kwan JL, Lo L, Sampson M, et al. Medication reconciliation during transitions of care as a patient safety strategy: a systematic review. Ann Intern Med 2013;158:397-403.

4. Rozich J, Resar R. Medication safety: one organization's approach to the challenge. JCOM 2001;8:27-34.

5. Aspden P, Wolcott J. Committee on Identifying and Preventing Medication Errors. Preventing medication errors: quality chasm series: The National Academies Press, 2007.

6. Belda-Rustarazo S, Cantero-Hinojosa J, Salmeron-García A, et al. Medication reconciliation at admission and discharge: an analysis of prevalence and associated risk factors. Int $J$ Clin Pract 2015;69:1268-74.

7. Coleman EA, Smith JD, Raha D, et al. Posthospital medication discrepancies: prevalence and contributing factors. Arch Intern Med 2005;165:1842-7.

8. Forster AJ, Murff HJ, Peterson JF, et al. The incidence and severity of adverse events affecting patients after discharge from the hospital. Ann Intern Med 2003;138:161-7.

9. How-to guide: prevent adverse drug events by implementing medication reconciliation. Cambridge, MA: Institute for Healthcare Improvement, 2001.

10. Agency for Healthcare Research and Quality. Medication reconciliation. Patient safety primer. https://psnet.ahrq.gov/primers/ primer/1/medication- reconciliation?q=medication+reconciliation (accessed 13 Nov 2017)

11. Murphy EM, Oxencis CJ, Klauck JA, et al. Medication reconciliation at an academic medical center: implementation of a comprehensive program from admission to discharge. Am J Health Syst Pharm 2009;66:2126-31.

12. Scarsi KK, Fotis MA, Noskin GA. Pharmacist participation in medical rounds reduces medication errors. Am J Health Syst Pharm 2002;59:267-70.

13. Karnon J, Campbell F, Czoski-Murray C. Model-based costeffectiveness analysis of interventions aimed at preventing medication error at hospital admission (medicines reconciliation). J Eval Clin Pract 2009;15:299-306. 